\title{
DIAGNÓSTICO DA IMPLANTAÇÃO DA ARBORIZAÇÃO DE RUAS NO BAIRRO SANTA QUITÉRIA, CURITIBA - PR
}

\author{
Angeline Martini ${ }^{1}$, Rozimeiry Gomes Bezerra Gaspar², Daniela Biondi ${ }^{3}$
}

\section{RESUMO}

O objetivo desta pesquisa foi realizar um diagnóstico da implantação da arborização de ruas no bairro Santa Quitéria, Curitiba. Para isso foram analisados: a procedência e uso da espécie plantada, altura total e de bifurcação da muda, presença de tutor, injúrias por vandalismo, percentual de mortalidade por vandalismo ou morte natural, condição fitossanitária, presença de brotações laterais abaixo da primeira bifurcação da muda, adequação da espécie com a largura da calçada e da via, adequação do porte da árvore à presença de fiação elétrica, área permeável disponível na base da planta e distância da planta ao meio fio. Os resultados mostram que a frequência de Handroanthus chrysotrichus (36,52\%) e Tibouchina pulchra (28,65\%) extrapolou o recomendado. A prefeitura selecionou essas duas espécies para plantio em calçadas com fiação elétrica, o que pode ter provocado o seu uso excessivo. As mudas utilizadas, não seguem o padrão da prefeitura, $50 \%$ destas apresentam altura total inferior a 2 metros e $92 \%$ dos indivíduos apresentam altura de bifurcação inferior a 1,80 metros. A área permeável na base da planta e a distância do plantio da muda ao meio fio satisfazem as recomendações. Conclui-se, que o planejamento da arborização no bairro Santa Quitéria não foi satisfatório.

Palavras-chave: Arborização urbana; Inventário arbóreo; Padrão de mudas; Tibouchina pulchra; Handroanthus chrysotrichus.

\footnotetext{
Recebido em 14.05.2012 e aceito em 03.04.2014

1 Engenheira Florestal, MSc., Doutoranda do Programa de Engenharia Florestal da UFPR. Curitiba/PR. Email: martini.angeline@gmail.com

2 Engenheira Florestal, Professora do Departamento Ciências Florestais, UFPR - Curitiba/PR. gasparebezerra@hotmail.com

3 Engenheira Florestal, Professora Associada IV do Departamento de Ciências Florestais, UFPR, Bolsista Produtividade em Pesquisa - CNPq, Curitiba/PR. dbiondi@ufpr.br
} 


\section{DIAGNOSTIC OF THE IMPLEMENTATION OF THE STREET TREES ON SANTA QUITÉRIA NEIGHBORHOOD IN CURITIBA - PR.}

\section{ABSTRACT}

The objective of this research was to conduct an assessment of the implementation of the street trees in the Santa Quitéria neighborhood, Curitiba. For it was analyzed: the origin and use of species planted, total height and bifurcation of seedlings, presence of a tutor, injuries due to vandalism, the mortality rate for vandalism or natural death, phytosanitary status, presence of buds below the first bifurcation of seedlings, adaptation of the species with the width of the sidewalk and road, adequacy of the size of the tree to the presence of electrical wiring, permeable area available at the base of the plant and away from the plant to the curb. The results show that the frequency of Handroanthus chrysotrichus (36.52\%) and Tibouchina pulchra $(28.65 \%)$ went beyond the recommended. The prefecture selected these two species for planting on sidewalks with electrical wiring, which may have caused its overuse. The seedlings used, do not follow the pattern of prefecture hall, $50 \%$ of present total height less than 2 meters and $92 \%$ of individuals present bifurcation height less than 1.80 meters. The permeable area at the base of the plant and the seedling planting distance from the curb meet the recommendations. It is concluded that the planning of street trees in the Santa Quitéria neighborhood was not satisfactory.

Keywords: Urban forestry; Tree inventory; Standard seedlings; Tibouchina pulchra; Handroanthus chrysotrichus.

\section{INTRODUÇÃO}

O uso da arborização é uma importante ferramenta para atenuar diversos problemas, uma vez que através de seus benefícios estéticos, sociais e ecológicos proporciona melhores condições de vida para o ser humano.

Lell (2006), afirma que os estudos em arborização urbana têm permitido aprofundar o conhecimento sobre a interação entre arborização e meio urbano, bem como seu manejo, dando lugar a diversas informações que permitem aperfeiçoar as tomadas de decisões. 
Assim, ressalta-se ainda, que quanto mais o processo de urbanização respeitar os limites naturais do meio e torná-lo organizado, mais eficiente é o planejamento da arborização urbana (BIONDI; ALTHAUS, 2005).

Quando não se realiza um planejamento apropriado da arborização, os benefícios ficam comprometidos, podendo apresentar eventuais transtornos, tais como: o rompimento de fios de alta-tensão, interrupções no fornecimento de energia elétrica, entupimento em redes de esgotos, obstáculos na acessibilidade e acidentes envolvendo pedestre, veículos ou edificações (SILVA FILHO et al., 2002). Deste modo, a falta de planejamento irá ocasionar grandes despesas para o poder público, com serviços e gastos como manutenção, podas frequentes, substituição, remoção e emprego de mão-de-obra excessiva (SILVA, 2005).

Biondi e Leal (2008) ressaltam que para esse planejamento da arborização, as características das espécies que irão compor a cobertura vegetal pública devem ser criteriosamente analisadas, antes mesmo de serem produzidas em viveiros. Atenção especial deve ser dada também ao conhecimento da estrutura urbana da cidade, para não haver conflito entre árvore e ambiente.

A cada dia se torna mais necessário a elaboração de um plano de arborização, baseado no estabelecimento de árvores bem distribuídas nas ruas, aproveitando os benefícios da planta para o meio e para as necessidades humanas, na busca por qualidade de vida (MILLER, 1997). Atualmente, esse planejamento da arborização é realizado pelas prefeituras através de um documento, conhecido como Plano Diretor da Arborização Urbana - PDAU.

Segundo Araujo e Araujo (2011), um Plano Diretor da Arborização Urbana resulta de um planejamento detalhado, contendo as diretrizes, metas, ações e normas, para a realização de objetivos de curto e longo prazo. Precisa ser baseado em um sistema de inventário dinâmico; demonstrar os valores da comunidade; estabelecer metas; prioridades para as atividades de plantio e manutenção e o estabelecimento de uma política de remoção e reposição de árvores. Deste modo, as vantagens que um PDAU bem desenvolvido pode apresentar são: menos interferência das árvores nos prédios e construções; menores problemas com doenças; menor manutenção e menores custos em termos de podas de limpeza e manutenção e remoção de árvores; menores danos nas calçadas; uma arborização esteticamente mais agradável; maior segurança para o público; e menores estragos e interferências nas linhas de transmissão de eletricidade, telefonia e TV a cabo.

$\mathrm{Na}$ cidade de Curitiba, os gestores e planejadores desenvolveram este documento e recentemente deram início a sua implantação em alguns bairros, entre eles o Santa Quitéria. 
Bairro, que segundo o Censo 2010 apresenta uma população total de 12.075 habitantes, distribuídos em uma área de $2.088 .000 \mathrm{~m}^{2}$ (INSTITUTO DE PESQUISA E PLANEJAMENTO URBANO DE CURITIBA, 2012). Em suas ruas são encontradas uma grande variedade de árvores e arbustos adultos, sem nenhuma padronização de plantio. Atrelado ao fato de ser um bairro antigo e basicamente residencial, pode-se afirmar, que em sua maioria, a arborização atual existente no bairro é resultado de uma atividade que não foi planejada, mas sim inserida pelos moradores.

Ao contrário de outras grandes cidades o Plano Diretor de Arborização Urbana de Curitiba ainda não foi disponibilizado ao público, o que impossibilita o desenvolvimento de uma avaliação técnico-científica. Paralelo a isto, observa-se em algumas situações, o plantio de mudas realizado de maneira inadequada nas ruas da cidade. Tendo em vista aos diversos fatores relacionados com o desenvolvimento das árvores, o objetivo deste trabalho foi realizar um diagnóstico da implantação da arborização de ruas no bairro Santa Quitéria, em Curitiba - PR.

\section{MATERIAIS E MÉTODOS}

\section{Área de estudo}

O presente trabalho foi realizado no bairro Santa Quitéria, na cidade de Curitiba-PR, a aproximadamente $25^{\circ} 46^{\prime} 04^{\prime \prime}$ de latitude sul e $49^{\circ} 31^{\prime} 18^{\prime \prime}$ de longitude oeste. A capital paranaense localiza-se no Primeiro Planalto a uma altitude média de 934,6 m acima do nível do mar. Segundo a classificação de Köppen, a cidade de Curitiba localiza-se em região climática do tipo $\mathrm{Cfb}$, com clima subtropical úmido, mesotérmico, sem estação seca, com verões frescos e invernos com geadas freqüentes e ocasionais precipitações de neve (IPPUC, 2012).

\section{Amostragem}

A quantificação e a qualificação da arborização urbana, obtida por meio de inventários, podem ser feitas por amostragens ou censo, sendo que esse último, por avaliar toda a população, só se justifica para análise quantitativa (NUNES, 1992).

O levantamento quali-quantitativo foi realizado através de amostragem das mudas plantadas nas vias públicas do Bairro Santa Quitéria, município de Curitiba PR. Adotou-se 
uma amostragem das mudas plantadas pelo fato de se considerar apenas o aspecto qualitativo e não quantitativo. Neste bairro já existem árvores adultas plantadas nas vias públicas e neste trabalho só foram avaliadas as mudas recentemente plantadas pela Prefeitura de Curitiba.

Para a realização do trabalho utilizou-se como base cartográfica o mapa da Regional Portão disponibilizado pelo IPPUC (2005) na escala aproximada de 1: 30.000. Neste mapa foram plotadas parcelas de $500 \times 250 \mathrm{~m}$, sobre toda a extensão do bairro, acompanhando as quadrículas já existentes. Foram tomadas cinco amostras aleatoriamente para avaliar a condição do plantio das mudas recém plantadas. A área coberta por essas cinco amostras totalizam $30 \%$ da área total do bairro (Figura 1).

Figura 1. Esboço da área amostral no bairro Santa Quitéria - Curitiba - PR

Figure 1. Sketch of the sampling area in the neighborhood Santa Quitéria - Curitiba - PR

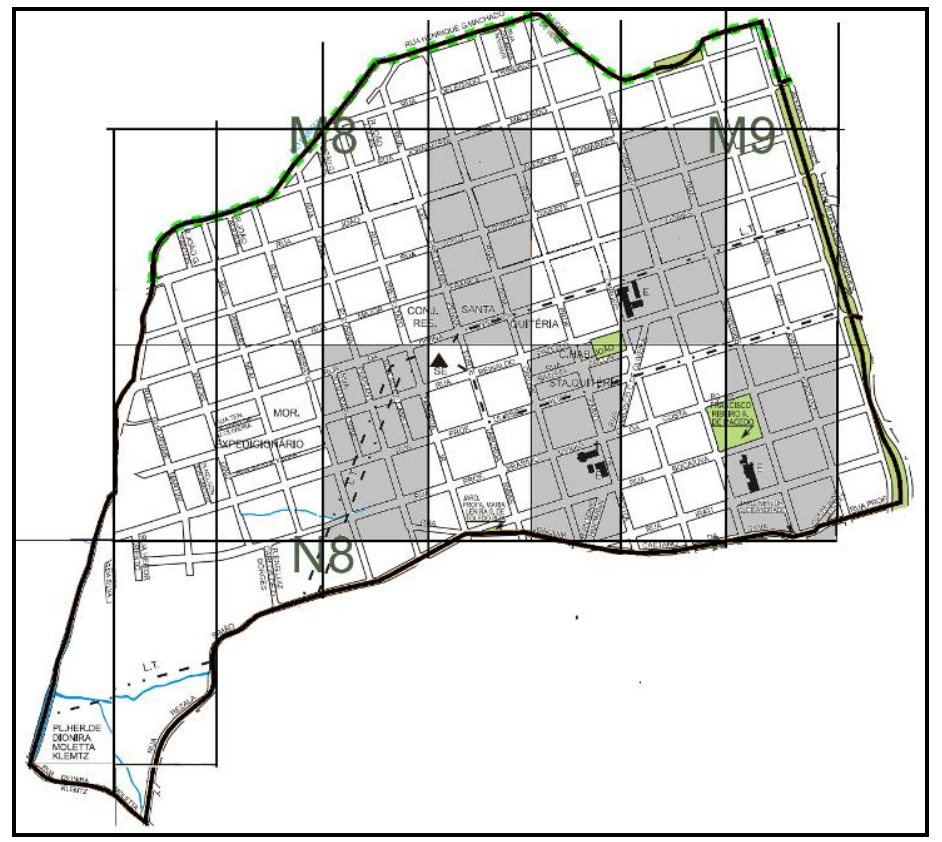

Fonte: Adaptado de IPPUC (2005).

\section{Análise das condições das ruas e de plantio}

Nos locais onde as mudas estão plantas foram realizadas medições e observações para verificar a adequabilidade da condição de plantio. Os fatores avaliados em campo foram:

a) largura da via - com a utilização da trena foi medido a distância de um meio-fio ao outro, determinando a largura da pista de rolamento; 
b) largura e estrutura da calçada - mediu-se a distância total entre o meio fio e o muro da casa, em ambos os lados da rua, para determinar a largura da calçada. A estrutura da calçada foi determinada com a medição, quando existente, das larguras do canteiro próximo ao meio fio (faixa de serviço), do passeio (faixa livre) e do canteiro próximo ao muro da casa (faixa de acesso);

c) localização da fiação elétrica - observou-se o lado da rua em que a fiação passa, a altura dos fios foi estimada visualmente e o posicionamento foi determinado pela distância entre a projeção visual da fiação no solo e o meio fio;

d) posicionamento do plantio - observou-se o lado em que as mudas foram plantadas e com o uso de trena foi medida a distância entre o meio fio e a muda;

e) área de canteiro - a área do canteiro foi determinada com a medição de suas dimensões;

O espaçamento entre árvores não foi medido por ser muito variável nas amostras, uma vez que muitas mudas foram vandalizadas (não são mais encontradas) e também por existirem árvores já adultas entre elas. A coleta dessas informações citadas permitiu a elaboração dos perfis das ruas amostradas, o que facilita na análise de adequação dos padrões de arborização empregados. A adequabilidade do plantio foi determinada a partir da análise nos seguintes quesitos:

a) adequação da espécie com a largura da calçada e via - buscou-se, através de pesquisa bibliográfica, determinar a altura e o diâmetro de copa máximo que as espécies podem alcançar. Os critérios para adequabilidade adotados podem ser observados na Tabela 1. A relação com a largura da via foi abordada apenas para o efeito visual, verificando se as espécies apresentam alguma incompatibilidade em relação as suas dimensões.

b) adequação do porte da árvore à presença de fiação elétrica - adotou-se como critério a indicação da Prefeitura da Cidade de São Paulo (2005) e da Companhia de Eletricidade do Estado da Bahia (2002) que recomendam sob fiação elétrica, o plantio de espécies de pequeno porte.

c) área permeável disponível na base da planta - segundo Santos e Teixeira (2001) e Gonçalvez e Paiva (2006), a área do canteiro deve ser de no mínimo $1 \mathrm{~m}^{2}$. Porém a Secretaria Municipal do Verde e do Meio Ambiente de São Paulo (2005) recomenda área de 2,0 $\mathrm{m}^{2}$ para árvores de pequeno porte e de 3,0 $\mathrm{m}^{2}$ para os demais portes.

d) distância da planta ao meio fio - o afastamento que deve existir entre a muda e o meio fio deve ser de no mínimo 50 cm (LELL, 2006; GONÇALVES; PAIVA, 2006; CESP, 1988). 
Tabela 1. Critérios adotados para adequabilidade do plantio

Table 1. Criteria for suitability of the planting

\begin{tabular}{c|c|c|c}
\hline Calçadas & $\begin{array}{c}\text { Altura da } \\
\text { árvore }\end{array}$ & Porte & $\begin{array}{c}\text { Diâmetro de } \\
\text { copa da árvore }\end{array}$ \\
\hline$<3,5 \mathrm{~m}$ & Até $6 \mathrm{~m}$ & Pequeno & Até $4 \mathrm{~m}$ \\
$3,5 \mathrm{~m}$ a $5,5 \mathrm{~m}$ & $6 \mathrm{~m}$ à $15 \mathrm{~m}$ & Médio & $4 \mathrm{~m} \mathrm{a} 6 \mathrm{~m}$ \\
$>5,5 \mathrm{~m}$ & $15 \mathrm{~m}$ & Grande & $>6 \mathrm{~m}$ \\
\hline
\end{tabular}

Fonte: Baseado em Guarnaschelli e Garau (2009).

\section{Avaliação das espécies utilizadas}

O levantamento de campo foi realizado aproximadamente seis meses após o plantio das mudas, durante o mês de dezembro de 2011. Buscou-se determinar a adequabilidade do planejamento da nova arborização implantada. Para isso, foram avaliadas somente as mudas plantadas pela Prefeitura de Curitiba, mudas fora do padrão da Secretaria de Arborização Urbana de Curitiba, espécies tradicionalmente não utilizadas em arborização urbana, foram desconsideradas nesta avaliação.

A avaliação foi realizada através de atributos para verificar se as amostras atendiam ou não ao padrão de muda desejado, sendo analisadas as seguintes características:

a) identificação, procedência e uso da espécie plantada - foi identificada a espécie plantada, constando o nome popular, científico, a família a que pertence, número total de espécies utilizadas na arborização, e a sua classificação como exótica, nativa do Brasil e de Curitiba. A identificação das espécies foi feita conforme descrição na literatura (LORENZI, 2008; LORENZI et al., 2003). A identificação das famílias foi realizada de acordo com a classificação de Engler. E a determinação da procedência e indicação de uso foi realizada com base em Biondi e Leal (2008).

b) altura total da muda - mediu-se a altura total da muda (do nível do solo até a parte mais alta da copa) em metros, sendo adotado como altura total mínima da muda de 2,00 m, baseando no padrão definido pela Secretaria de Urbanismo do município de Curitiba. A avaliação foi realizada com o auxílio de uma trena, mas para a análise foi considerada como um atributo se este era atendido ao padrão ou não.

c) altura de bifurcação da muda - mediu-se a altura da primeira bifurcação da muda (do nível do solo até a primeira bifurcação do fuste), em metros. Avaliou-se dentro do padrão recomendado a altura da primeira bifurcação igual ou superior a 1,80 m, valores inferiores a este foram considerados fora do padrão. A avaliação foi realizada com o auxílio de uma 
trena, mas para a análise foi considerada como um atributo se este era atendido ao padrão ou não.

d) presença de tutor na muda - avaliou-se a presença ou ausência de tutores nas mudas plantadas.

e) injúrias por vandalismo - avaliou-se a presença ou ausência de injúrias mecânicas nas mudas em consequência de vandalismo.

f) percentual de mortalidade por vandalismo ou morte natural - avaliou-se o percentual de mortalidade das mudas decorrentes de vandalismo ou morte natural.

g) condição fitossanitária - a condição fitossanitária dos indivíduos foi classificada em: presença (infestação de pragas ou doenças) ou ausência (sem infestação de pragas ou doenças).

h) presença de brotações laterais abaixo da primeira bifurcação da muda - verificouse a ocorrência de brotações laterais abaixo da primeira bifurcação e a existência ou não da poda de manutenção destas. Esta prática silvicultural objetiva garantir o desenvolvimento mais retilíneo e melhor formação da copa da árvore na rua.

\section{RESULTADOS E DISCUSSÕES}

\section{Avaliação das espécies plantadas}

Foram amostradas 176 mudas, plantadas no Bairro Santa Quitéria em Curitiba - PR. Estas mudas foram classificadas em nove espécies (Figura 2) e encontram-se distribuídas em seis famílias. Destas nove espécies plantadas somente uma é exótica, extremosa (Lagerstroemia indica L.) e uma nativa de Curitiba, dedaleiro (Lafoensia pacari A. St.-Hil.), as demais são nativas do Brasil. O ipê-amarelo (Handroanthus chrysotrichus (Mart. Ex A. DC.) Mattos) e a quaresmeira (Tibouchina pulchra (Cham.) Cogn.) foram as espécies mais plantadas, representando $36,52 \%$ e $28,65 \%$ do total, respectivamente (Tabela 2).

Conforme Grey e Deneke (1986), uma única espécie não deve representar mais que $10-15 \%$ da população total da arborização de ruas. Para evitar problemas e prejuízos com o ataque severo de pragas, Santamour (1990) recomenda que a composição de espécies não passe de $30 \%$ para a mesma família, 20\% para um mesmo gênero e $10 \%$ para a mesma espécie. 
Figura 2. Mudas das espécies encontradas no bairro Santa Quitéria

Figure 2. Seedlings of the species found in the neighborhood Santa Quitéria
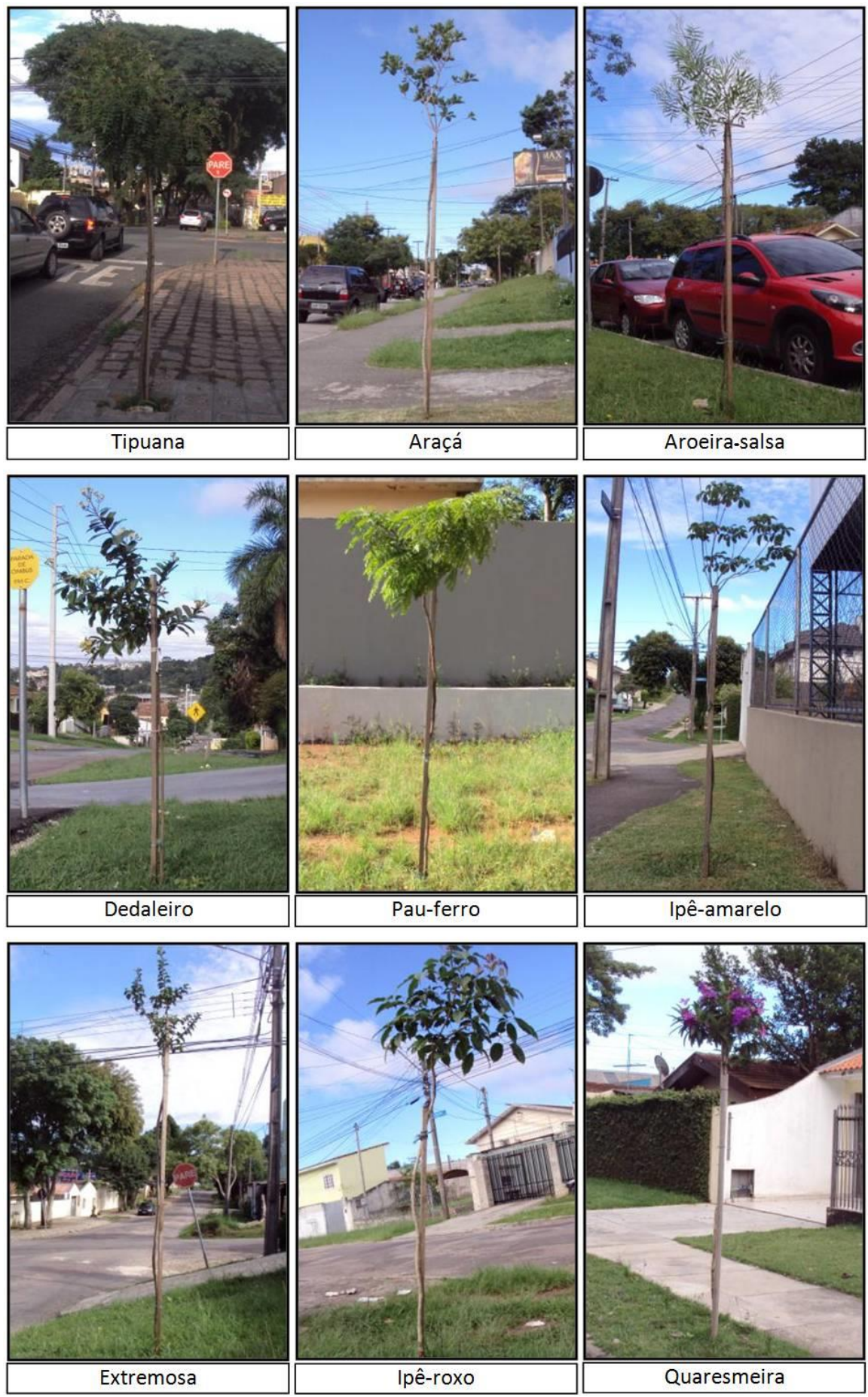

Deste modo a alta percentagem de utilização de Handroanthus chrysotrichus e Tibouchina pulchra na amostra pode ser indício de futuros problemas. Estes são ainda mais graves no que se refere ao uso de Handroanthus chrysotrichus, uma vez que a espécie já é uma das mais plantadas desde 1984 (MILANO, 1984), sendo que no ano de 2010 foi 
constatado que esta é a terceira espécie mais frequente na arborização de Curitiba (BOBROWSKI, 2011). Milano (1984) recomenda a redução na frequência de plantio desta espécie, em função de mais de 50\% do total de árvores amostradas apresentaram problema de pragas e/ou doença.

Tabela 2. Relação das espécies recém-plantadas no bairro Santa Quitéria, Curitiba - PR Table 2. List of newly-planted species in the neighborhood Santa Quitéria, Curitiba - PR

\begin{tabular}{|c|c|c|c|c|c|}
\hline \multirow[b]{2}{*}{ Família } & \multicolumn{2}{|l|}{ Espécie } & \multirow[b]{2}{*}{ Procedência* } & \multirow[b]{2}{*}{ Uso* } & \multirow{2}{*}{$\begin{array}{c}\text { Frequência } \\
\text { (\%) }\end{array}$} \\
\hline & Nome Científico & $\begin{array}{l}\text { Nome } \\
\text { Comum }\end{array}$ & & & \\
\hline Anacardiacea & Schinus molle L. & Aroeira-salsa & $\begin{array}{c}\text { Nativa do } \\
\text { Brasil }\end{array}$ & $\mathrm{AV}, \mathrm{AB}$ & 8,43 \\
\hline Bignoniaceae & $\begin{array}{c}\text { Handroanthus chrysotrichus } \\
\text { (Mart. Ex A. DC.) Mattos }\end{array}$ & Ipê-amarelo & $\begin{array}{c}\text { Nativa do } \\
\text { Brasil }\end{array}$ & $\begin{array}{c}\mathrm{R}, \mathrm{AV} \\
\mathrm{AB}\end{array}$ & 36,52 \\
\hline Bignoniaceae & $\begin{array}{c}\text { Handroanthus heptaaphyllus } \\
\text { (Vell.) Mattos }\end{array}$ & Ipê-roxo & $\begin{array}{c}\text { Nativa do } \\
\text { Brasil }\end{array}$ & $\begin{array}{c}\mathrm{R}, \mathrm{AV} \\
\mathrm{AB}\end{array}$ & 1,1 \\
\hline Fabaceae & $\begin{array}{c}\text { Caesalpinia ferrea var. } \\
\text { leiostachya Benth. }\end{array}$ & Pau-ferro & $\begin{array}{c}\text { Nativa do } \\
\text { Brasil }\end{array}$ & $\begin{array}{c}\mathrm{R}, \mathrm{AV} \\
\mathrm{AB}\end{array}$ & 3,93 \\
\hline Fabaceae & $\begin{array}{c}\text { Tipuana tipu } \\
\text { (Benth.) Kuntze }\end{array}$ & Tipuana & $\begin{array}{c}\text { Nativa do } \\
\text { Brasil }\end{array}$ & $\begin{array}{c}\mathrm{R}, \mathrm{AV} \\
\mathrm{AB}\end{array}$ & 1,12 \\
\hline Lithraceae & Lagerstroemia indica L. & Extremosa & Exótica & $\mathrm{R}, \mathrm{AV}$ & 2,81 \\
\hline Lithraceae & $\begin{array}{l}\text { Lafoensia pacari } \\
\text { A. St.-Hil. }\end{array}$ & Dedaleiro & $\begin{array}{l}\text { Nativa de } \\
\text { Curitiba }\end{array}$ & $\begin{array}{c}\mathrm{R}, \mathrm{AV} \\
\mathrm{AB}\end{array}$ & 5,06 \\
\hline Melastomataceae & $\begin{array}{l}\text { Tibouchina pulchra (Cham.) } \\
\text { Cogn. }\end{array}$ & Quaresmeira & $\begin{array}{l}\text { Nativa do } \\
\text { Brasil }\end{array}$ & $\begin{array}{c}\mathrm{R}, \mathrm{AV} \\
\mathrm{AB}\end{array}$ & 28,65 \\
\hline Myrtaceae & Psidium cattleyanum Sabine & Araçá & $\begin{array}{c}\text { Nativa do } \\
\text { Brasil }\end{array}$ & $\mathrm{AV}, \mathrm{AB}$ & 12,36 \\
\hline
\end{tabular}

Na Tabela 2, pode ser observado, conforme recomendações de Biondi e Leal (2008), que para cada espécie encontrada existe a indicação do melhor local para se plantar, tais como: na rua $(R)$, em área verde $(A V)$ e adensamento de bosque $(A B)$. Seguindo esta recomendação, as únicas espécies que estão em desacordo para o plantio em rua são o araçá (Psidium cattleianum) e a aroeira-salsa (Schinus molle).

Duas das espécies encontradas, a aroeira-salsa (Schinus molle) e extremosa (Lagerstroemia indica), não são recomendadas para o plantio em vias públicas por serem eventualmente tóxicas aos transeuntes, de acordo com Santos e Teixeira (2001) e Biondi e Leal (2008), muito embora a COPEL (2012) indique a aroeira-salsa para arborização de rua. 
Três das espécies plantadas atraem a avifauna, araçá (Psidium cattleianum), aroeira-salsa (Schinus molle) e ipê-amarelo (Handroanthus chrysotrichus).

A tipuana (Tipuana tipu) é uma árvore de grande porte, e apresenta controvérsia quanto ao seu uso. Santos e Teixeira (2001), não recomendam o seu plantio em calçadas porque possui sistema radicular superficial e agressivo. Entretanto a Copel (2012) indica para arborização de rua.

O mesmo acontece com o pau-ferro, a COPEL (2012) indica o uso de pau-ferro (Caesalpinia ferrea var. leiostachya) para arborização de rua devido a beleza de seu tronco e do formato de suas folhas, entretanto Lorenzi (2008) e a Prefeitura da Cidade De São Paulo (2005) recomendam que seja utilizada em canteiros centrais com mais espaço para o seu desenvolvimento em função dos ramos quebrarem com facilidade pelo vento.

Todas as mudas encontravam-se com tutores de condução. $\mathrm{Na}$ avaliação da condição fitossanitária, as mudas avaliadas apresentaram-se $100 \%$ na categoria boa, sem ocorrência de infestação de pragas e doenças. No entanto, de acordo com Biondi (2011), na fase adulta o ipê-amarelo (Handroanthus chrysotrichus), na arborização de rua em Curitiba, apresenta grande infestação de doenças.

Para que se tenha uma melhor adaptação das mudas no local de plantio definitivo e que sejam menos sujeitas ao vandalismo, existem recomendações a respeito do tamanho mínimo destas. Este tamanho mínimo pode variar de 2 até superior a 3 metros de altura, dependendo muito do município em que se encontra (COPEL, 2012; PREFEITURA MUNICIPAL DE PORTO ALEGRE, 1996; CESP, 1988; PREFEITURA DE PIRACICABA, 2007; PREFEITURA DA CIDADE DE SÃO PAULO, 2005; FERRAZ; NOGUEIRA, 2009).

Na Prefeitura Municipal de Curitiba é adotado o tamanho mínimo de 2,00 m, mesmo assim, conforme informações informais emitidas por seus técnicos, a cada 100 mudas plantadas 50 são depredadas por vândalos. Estudos comprovam que mudas menores estão mais sujeitas ao vandalismo por isso é estipulado um tamanho mínimo para o plantio nas calçadas.

Das mudas avaliadas foi verificado que $50 \%$ estavam iguais ou acima de 2,00 m de altura total e $8,4 \%$ estavam iguais ou acima de $1,80 \mathrm{~m}$ de altura da primeira bifurcação. Das 51 mudas de quaresmeira plantadas, 59\% encontravam-se quebradas em função de atos de vandalismo. Este fato pode estar correlacionado com o tamanho fora do padrão destas, já que menos que $2 \%$ destas mudas tinham altura total igual ou superior a $2,00 \mathrm{~m}$ e $8,9 \%$ possuíam altura da primeira bifurcação acima de 1,80 m. O índice de mortalidade por vandalismo de todas as espécies plantadas foi de $1,7 \%$ do total. 
Observou-se que todas as mudas plantadas apresentavam-se com brotações laterais, abaixo da copa conduzida no viveiro. Fato que pode afetar o bom desenvolvimento das mudas, caso não se tenha uma prática de desrama de brotações após o plantio definitivo. Além disso, isto comprometer o investimento que se faz no viveiro ao conduzir uma copa mais alta e bem formada. Diante disto, é recomendável estudar a prática de poda de condução (desrama lateral) das mudas após o plantio definitivo para garantir árvores bem conduzidas na arborização de rua. De acordo com a COPEL (2012) e a Prefeitura da Cidade de São Paulo (2004) é recomendado esta prática, denominada de poda de condução ou formação, cuja função é direcionar o desenvolvimento da copa aos espaços disponíveis e livrar o tronco de ramificações indesejadas e de brotações laterais.

A avaliação de plantios realizados pela comunidade foi evidenciado através da distinção destas com as espécies plantadas pela Prefeitura de Curitiba. Além disso, o padrão das espécies estavam totalmente fora do recomendado.

\section{Condições de plantio}

As cinco parcelas instaladas abrangeram 26 ruas, destas foi constatado o plantio de mudas em 19, sendo elas: Bocaiúva, Capiberibe, Cel. Airton Plaisant, Cel. Pretextato Penna, Divina Providência, Dom Orione, Dona Eleusiana Plaisant, Fabio de Souza, Irati, João Alencar Guimarães, João Scuisstato, Joaquim Caetano, Jornalista Caio Machado, Julio Eduardo Gineste, Major França Tetto, Pretextato Taborda Jr., Prof. Brasilio Ovídio da Costa, Reinaldo Pazello e Ulisses Vierira.

O perfil da rua pôde ser determinado para 11 destas 19 ruas (Figura 3), para as demais não foi possível devido à falta de algumas informações. As ruas Capiberibe, Cel. Pretextato Penna, João Scuisstato e Jornalista Caio Machado não foram apresentadas porque apresentaram mudas apenas em um lado da via. Dentro das amostras, as ruas Dona Eleusiana Plaisant, Fabio de Souza e Joaquim Caetano não apresentam calçadas ou meio fio (Figura 4). E na rua Major França Gomes foi plantado apenas um indivíduo para manter a arborização já existente.

Com base na Figura 3 observa-se que Handroanthus chrysotrichus foi a espécie mais utilizada, compondo sete dos onze perfis encontrados. Tibouchina pulchra aparece em segundo lugar, sendo utilizada em quatro perfis. O plantio homogêneo, mesma espécie em ambos os lados, foi predominante em seis perfis. E ainda com base na Figura 4, é possível notar algumas situações inadequadas ou que poderiam ser aperfeiçoadas, estas serão destacadas nos tópicos subseqüentes. 
Figura 3. Perfil das ruas amostradas

Figure 3. Profile of streets sampled

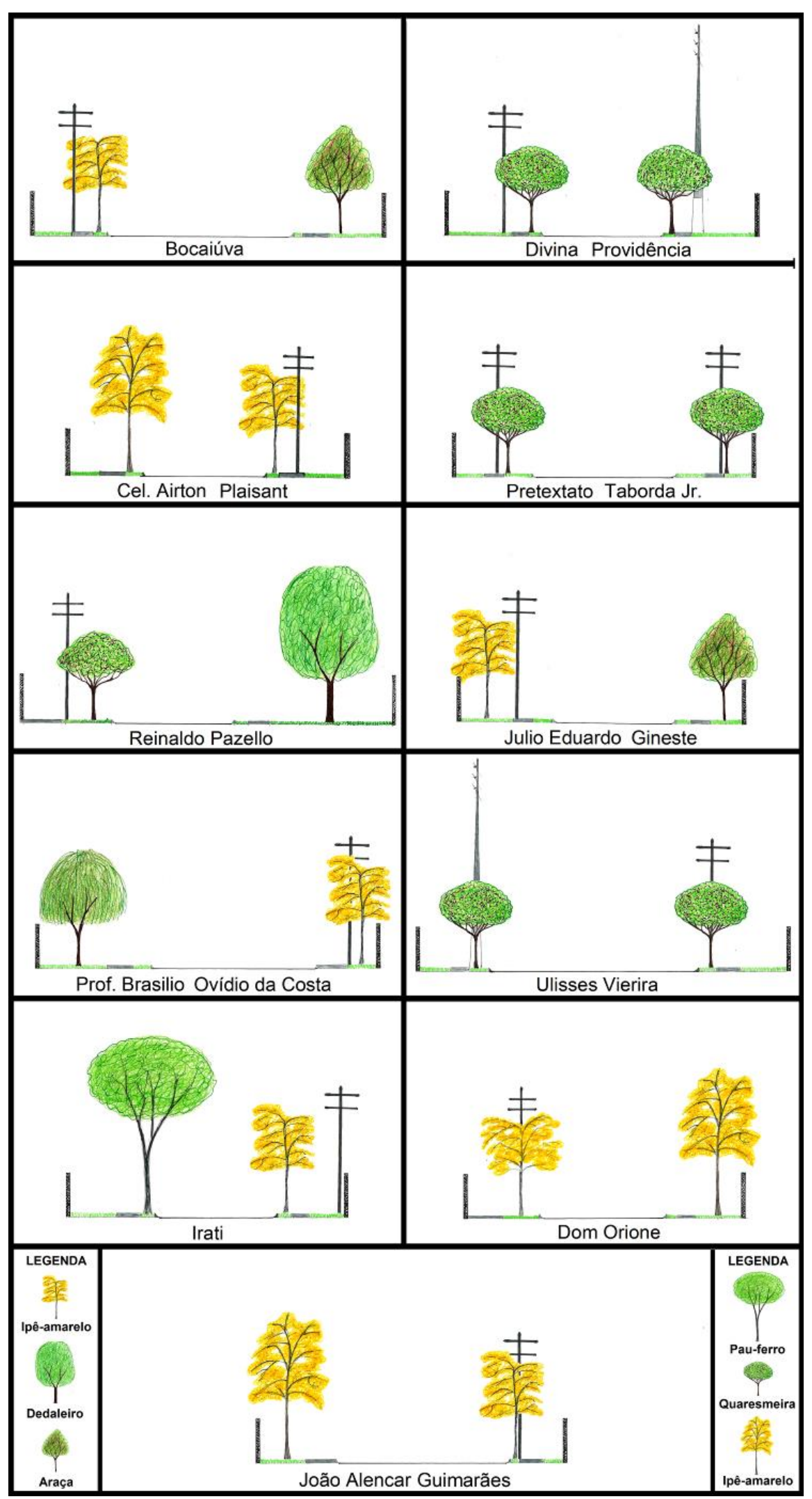


Figura 4. Exemplos de ruas amostradas que não apresentam infra-estrutura adequada para avaliação da condição de plantio

Figure 4. Examples of streets sampled that do not have the infrastructure appropriate forassessing the condition of planting
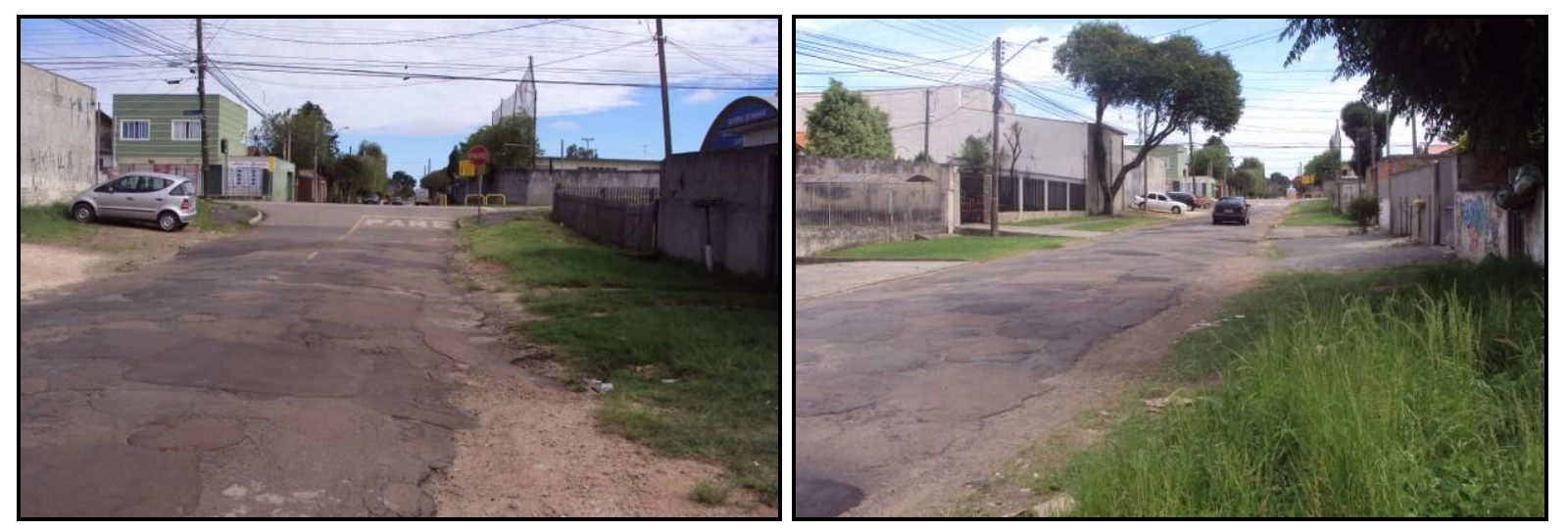

\section{Adequação da espécie com a largura da calçada e via}

Nas amostras realizadas há um predomínio de calçadas com dimensões médias (76,5\%), que são aquelas com largura entre 3,5 e 5,5 m. Já as calçadas largas totalizaram $14,7 \%$ e as estreitas $8,8 \%$. A maioria das ruas amostradas são largas, com dimensões superiores a 7 m (CEMIG, 1996), sendo encontradas apenas três com dimensões inferiores a este padrão, porém nenhuma foi representada na Figura 4.

Nas calçadas estreitas foram plantadas apenas as espécies Handroanthus chrysotrichus e Tibouchina pulchra, nas calçadas largas Lafoensia pacari, Schinus molle e Lagerstroemia indica e nas demais calçadas, foram plantadas todas as nove espécies.

Segundo classificação de Mesquita (1996), das nove espécies plantadas, três são de pequeno porte (Tibouchina pulchra, Psidium cattleyanum, Lagerstroemia indica), quatro de médio porte (Handroanthus chrysotrichus, Lafoensia pacari, Schinus molle e Handroanthus heptaaphyllus) e duas de grande porte (Caesalpinia ferrea var. leiostachya e Tipuana tipu). Desta forma, as espécies de pequeno porte deveriam ser plantadas nas calçadas estreitas, as de médio porte nas calçadas de dimensões médias e as de grande porte nas calçadas largas, o que não foi verificado na amostra realizada.

O uso de Handroanthus chrysotrichus e Tibouchina pulchra em calçadas estreitas é adequado, mesmo que Handroanthus chrysotrichus apresente dimensões maiores a recomendada, a espécie já é amplamente utilizada nesta situação e não apresenta problemas. O plantio de Lafoensia pacari, Schinus molle e Lagerstroemia indica em calçadas largas não oferecem problemas, porém nesta situação o espaço poderia ser 
melhor utilizado uma vez que possibilita o uso de espécies de grande porte, o que proporcionaria efeito estético, ecológico e social mais agradável.

Problema de inadequação entre o porte e a largura da calçada foi constatado nas calçadas de dimensões médias, onde foram plantadas todas as espécies, incluindo as de grande porte, Caesalpinia ferrea var. leiostachya e Tipuana tipu. Constata-se que a adequação entre o porte da espécie e a largura da calçada e via não foi levada em consideração na escolha da espécie a ser plantada. Por outro lado, a maioria das ruas apresentam calçadas com dimensões médias e nestas foram plantadas árvores de todos os portes.

Dos 176 indivíduos avaliados na amostra, 56,8\% estão plantados no lado da calçada que passa fiação elétrica, nesta situação as espécies utilizadas foram: Handroanthus chrysotrichus (46\%), Tibouchina pulchra (42\%), Schinus molle (6\%), Lagerstroemia indica (3\%), Psidium cattleyanum (2\%), e Caesalpinia ferrea var. leiostachya (1\%). Assim, menos da metade dos indivíduos plantados na calçada com fiação elétrica são de pequeno porte (47\%), do restante (espécies de médio e grande porte), 77\% está plantado a menos de dois metros da fiação, o que, devido ao diâmetro de copa dessas espécies, acarretará gastos futuros com podas.

O plantio de árvores de grande porte sob a rede elétrica é possível, desde que a muda não seja plantada no alinhamento da rede e que a copa das árvores seja conduzida precocemente, através do trato cultural adequado, acima dessa rede (PREFEITURA DA CIDADE DE SÃO PAULO, 2005).

Algumas das situações problemáticas com relação a fiação elétrica podem ser observadas na Figura 4. Como por exemplo, na rua Cel. Airton Plaissant, onde é possível notar a diferença no desenvolvimento de Handroanthus chrysotrichus que deverá ser submetida a poda devido a passagem de fiação elétrica. Conforme Bobrowski (2011), a espécie $H$. chrysotrichus não é indicada para plantio sob fiação devido ao caráter ortotrópico de sua arquitetura de copa.

$\mathrm{Na}$ rua Dom Orionde e João Alencar Guimarães observa-se o plantio de Handroanthus chrysotrichus exatamente no alinhamento dos postes, o que deformará completamente a copa da espécie, devido as podas freqüentes que serão necessárias para mantê-la abaixo da fiação. Segundo Leal (2007), as podas realizadas pela COPEL nas árvores que interferem na fiação aérea são realizadas a cada cinco anos na cidade de Curitiba, acarretando altos custos. 
Por fim, na rua Divina Providência e Ulisses vieira há a passagem de fiação de alta tensão, mais alta (aproximadamente $10 \mathrm{~m}$ ) do que a convencional, descartando a necessidade do plantio de espécie de pequeno porte, como foi realizado.

Segundo a COELBA (2002), as redes compactas com cabos protegidos constituem uma solução tecnológica que permite uma melhor convivência coma a arborização, pois permite toques eventuais de galhos de árvores sem provocar desligamentos de rede elétrica. Exigem menor freqüência de podas e requerem menor área de poda em comparação com as redes nuas ou redes convencionais protegidas por coberturas.

Contudo, pode-se afirmar que nesse aspecto houve um cuidado por parte dos planejadores, entretanto erros foram cometidos, como o uso extensivo das espécies Handroanthus chrysotrichus e Tibouchina pulchra. Logo, a escolha do uso dessas duas espécies sob a fiação elétrica é o provável motivo para a expressiva porcentagem de indivíduos encontrados em toda a amostra.

\section{Área permeável disponível a planta}

A área permeável disponível na base da planta, com exceção de um exemplar de Tipuana tipu que foi plantada em uma área de $0,1 \mathrm{~m}^{2}$, supera as recomendações de Santos e Teixeira (2001), Gonçalvez e Paiva (2006) e Prefeitura da Cidade de São Paulo (2005), pois a menor área de canteiro encontrada foi de $4 \mathrm{~m}^{2}$ e a maior atingiu $56 \mathrm{~m}^{2}$. Entretanto, mesmo a área sendo suficiente, observa-se em algumas situações que as dimensões dos canteiros não são satisfatórias, como nos locais onde a largura do canteiro é de apenas 0,50 $\mathrm{m}$.

Com base na Figura 4, observa-se que nas ruas Divina Providência, Cel Airton Plaissant, Ulisses Vieria, Irati e João Alencar Guimarães, poderia ter sido optado pelo plantio das mudas nos canteiros mais largos presentes na calçada, para aumentar a área permeável disponível à planta.

\section{Distância da planta ao meio fio}

Apenas duas mudas foram encontradas plantadas a menos de $0,50 \mathrm{~m}$ do meio fio, conforme recomendação de Lell (2006), Gonçalves e Paiva (2006) e CESP (1988). Assim, neste critério, pode-se afirmar que houve planejamento adequado. Embora, em algumas situações as mudas poderiam ter sido plantadas mais afastadas ao meio fio, seguindo 0 mesmo princípio da área permeável. O plantio de 51 mudas $(28,6 \%)$ poderia ter sido feito 
em outro canteiro, mais próximo da casa e assim mais distante do meio fio, pois em toda a amostra, as casas possuem recuo de quatro metros.

\section{CONCLUSÕES}

Das mudas recentemente plantadas nas ruas do bairro Santa Quitéria, que totalizam nove espécies, pode-se concluir que:

a) a freqüência de indivíduos plantados não segue o padrão recomendado, $10 \%$, este valor foi extrapolado para as espécies Handroanthus chrysotrichus $(36,52 \%)$ e Tibouchina pulchra $(28,65 \%)$.

b) as mudas utilizadas, em sua maioria, não seguem o padrão recomendado, $50 \%$ destas apresentam altura total inferior a 2 metros e 92\% dos indivíduos apresentam altura de bifurcação inferior a 1,80 metros.

c) a adequação entre o porte da espécie, largura da calçada e via, não foi levada em consideração, em algumas situações as ruas foram subutilizadas.

d) a prefeitura selecionou as espécies Tibouchina pulchra e Handroanthus chrysotrichus em calçadas com fiação elétrica, o que pode ter provocado o uso excessivo dessas espécies.

e) a área permeável na base da planta e a distância do plantio da muda ao meio fio satisfazem as recomendações.

\section{REFERÊNCIAS}

ALBERTIN, R. M.; DE ANGELIS, R.; DE ANGELIS NETO, G.; LUIZ, B.; DE ANGELIS, D.. Diagnóstico quali-quantitativo da arborização viária de Nova Esperança, Paraná, Brasil. Revista Brasileira de Arborização Urbana, Piracicaba, v. 6, n. 3, p. 128 - 148, 2011.

ARAUJO, M. N. de; ARAUJO, A. J. Arborização Urbana. Série de Cadernos Técnicos da Agenda Parlamentar. CREA - PR, 2011, 40 p.

BIONDI, D.; ALTHAUS, M.. Árvores de Rua de Curitiba - Cultivo e Manejo. Curitiba: FUPEF, 175 p., 2005. 
BIONDI, D.; LEAL, L.. Caracterização das Plantas Produzidas no Horto Municipal da Barreirinha - Curitiba - PR. Revista da Sociedade Brasileira de Arborização Urbana, Piracicaba-SP, 2008. v. 3, n. 2, p. 20 - 36.

BIONDI, D.. Notas de Aula da Disciplina de Arborização Urbana - Curitiba: Universidade Federal do Paraná, 2011. p.3.

BOBROWSKI, R.. Estrutura e dinâmica da arborização de ruas de Curitiba, Paraná, no Período 1984-2010. 2011. 144 f. Dissertação (Mestrado em Engenharia Florestal) Departamento de Ciências Florestais da Universidade Federal do Paraná, Curitiba, 2011.

COMPANHIA ENERGÉTICA DE MINAS GERAIS (CEMIG). Manual de arborização. Belo Horizonte - MG: CENTRAIS ELÉTRICAS DE MINAS GERAIS-CEMIG, 1996. 40 p.

COMPANHIA DE ELETRICIDADE DO ESTADO DA BAHIA (COELBA). Guia de Arborização Urbana. Salvador: Venture, 55 p., 2002.

COMPANHIA PARANAENSE DE ENERGIA (COPEL). Arborização de vias públicas. Guia para os municípios. Disponível em: <http://www.copel.com/hpcopel/guia_arb/index.html> Acesso em: 17/02/2012.

COMPANHIA DE ENERGIA DE SÃO PAULO (CESP). Guia de arborização. 3.ed. Coleção Ecossistemas Terrestres, 006. São Paulo: CESP, 1988. 33 p.

FERRAZ, M. V.; NOGUEIRA, D. M.. Arborização urbana para o município de RegistroSP. Palestras [do] 1. Workshop sobre Arborização Urbana no Vale do Ribeira, 26 de agosto de 2009/Editores técnicos: Marcelo Vieira Ferras e Hugo do Nascimento Bendini - Registro: UNESP Campus Experimental; Botucatu- SP: FEPAF, 2009. p. 68 - 71.

GONÇALVES, W.; PAIVA, H. N. de. Silvicultura Urbana: implantação e manejo. Viçosa, MG: Aprenda Fácil, Coleção jardinagem e paisagismo 4, Série arborização urbana, 2006, $201 \mathrm{p}$.

GREY, G. W.; DENEKE, F. J. Urban Forestry. 2. ed. New York: John Wiley, 1986. 299 p.

GUARNASCHELLI, A. B.; GARAU, A. M.. Árboles: Uma guia esencial para plantar y mantener diversas especies de árboles. Buenos Aires: Albatros, 2009. 112 p.

INSTITUTO BRASILEIRO DE GEOGRAFIA E ESTATÍSTICA (IBGE). Disponível em: <http://www.ibge.gov.br/home/estatistica/populacao/censo2010/tabelas_pdf/Brasil_tab_1_15 .pdf > Acesso em: 17/01/2012. 
INSTITUTO DE PESQUISA E PLANEJAMENTO URBANO DE CURITIBA (IPPUC). Curitiba em Dados. Disponível em:

<http://www.ippuc.org.br/Bancodedados/Curitibaemdados/Curitiba_em_dados_Pesquisa.htm $>$ Acesso em: 17/01/2012.

INSTITUTO DE PESQUISA E PLANEJAMENTO URBANO DE CURITIBA (IPPUC). Mapa da Regional Portão. [Curitiba], 2005, 1 mapa. Escala 1:30.000.

LEAL, L.. Custos das Árvores de Rua - Estudo de Caso: Cidade de Curitiba/PR. 2007. 115 f. Dissertação (Mestrado em Engenharia Florestal) - Departamento de Ciências Florestais da Universidade Federal do Paraná, Curitiba, 2007.

LELL, J. Arbolado Urbano: Implantación y cuidados de árboles para veredas. Buenos Aires: Orientación Gráfica Editora, 2006.

LORENZI, H.. Árvores Brasileiras: manual de identificação e cultivo de plantas arbóreas nativas do Brasil. v. 1, Nova Odessa, SP: Instituto Plantarum, 2008. 352 p.

LORENZI, H.; SOUZA, H. M. de; TORRES, M. A. V.; BACHER, L. B.. Árvores exóticas no Brasil: madeireiras, ornamentais e aromáticas. Nova Odessa, SP: Instituto Plantarum, 2003. $368 \mathrm{p}$.

MARTINI, A.. Estudo fenológico em árvores de rua. In: BIONDI, D.; LIMA NETO, E. M de. (Org.). Pesquisas em arborização de ruas. Curitiba: O Autor, 2011. p. 29 - 48.

MESQUITA, L. de B.. Arborização do Recife: Notas técnicas para ajustes na execução e manutenção. Recife: Editora Universitária UFPE, 88 p. 1996.

MILANO, M. S. Avaliação e análise da arborização de ruas de Curitiba. 1984. $130 \mathrm{f}$. Dissertação (Mestrado em Engenharia Florestal). Departamento de Ciências Florestais da Universidade Federal do Paraná, Curitiba, 1984.

MILLER, R. W.. Urban Forestry: Planning and Managing Urban Greenspaces. 2 ed. New Jersey, Prentice Hall, 1997. 502 p.

NUNES, M. L.. Metodologias de avaliação da arborização urbana. In: CONGRESSO BRASILEIRO DE ARBORIZAÇÃO URBANA, 1., ENCONTRO NACIONAL DOBRE ARBORIZAÇÃO URBANA, 4., Vitória, 1992. Anais. Vitória: Prefeitura Municipal de Vitória, 1992. p. $133-145$. 
PREFEITURA DA CIDADE DE SÃO PAULO. Manual Técnico de Poda de Árvores. São Paulo: Secretaria do Verde e do Meio Ambiente. Secretaria de Coordenação das Subprefeituras. Prefeitura de São Paulo. 2004. 32 p.

PREFEITURA DA CIDADE DE SÃO PAULO. Manual técnico de arborização urbana. 2.ed. São Paulo: Secretaria Municipal do Verde e do Meio Ambiente. Prefeitura de São Paulo. 2005. 48 p.

PREFEITURA DE PIRACICABA. Manual de Normas Técnicas de Arborização Urbana. Secretaria de Defesa do Meio Ambiente. Prefeitura Municipal de Piracicaba. Piracicaba, 2007. $48 \mathrm{p}$.

PREFEITURA MUNICIPAL DE PORTO ALEGRE. SECRETARIA MUNICIPAL DO MEIO AMBIENTE. Plano diretor de arborização de vias públicas e comunidade interativa para Porto Alegre. Porto Alegre: 1996. 34 p.

SANTAMOUR JÚNIOR, F. S.. Trees for urban planting: diversity, uniformity, and common sense. In: Metria Conference, 7., 1990, Lisle. Proceedings..., Lisle: METRIA, 1990. p. 57 66 .

SANTOS, N. R. Z.; TEIXEIRA, I. F.. Arborização de vias públicas: Ambiente x Vegetação. Instituto Souza Cruz, 1ํㅡㄹ. ed. Porto Alegre: Ed. Pallotti. 135 p., 2001.

SILVA, A. G. da.; PAIVA, H. N. de; GONÇALVES, W.. Avaliando a arborização urbana. Viçosa, MG: Aprenda Fácil, Coleção jardinagem e paisagismo 5, série arborização urbana, 2007, 346 p.

SILVA, L. F.. Situação da arborização viária e proposta de espécies para os bairros Antônio Zanaga I e II, da cidade de Americana-SP. 2005. 80 f.. Dissertação (Mestrado em Agronomia) - Universidade de São Paulo, Piracicaba, 2005.

SILVA FILHO, D. F. da; PIZETTA, P. U. C.; ALMEIDA, J. B. S. A. de; PIVETTA, K. F. L.; FERRAUDO, A. S.. Banco de dados relacional para cadastro, avaliação e manejo da arborização em vias públicas. Revista Árvore, Viçosa, v. 26, n. 5, p. 629 - 642, 2002. 